\title{
Effects of Glycerol and Sodium Pentaborate Formulation on Prevention of Postoperative Peritoneal Adhesion Formation
}

\author{
Erhan Aysan $\left(\mathbb{D},{ }^{1}\right.$ Fikrettin Sahin, ${ }^{2}$ Ruzgar Catal, ${ }^{3}$ Mirkhaliq Javadov, ${ }^{1}$ and Alev Cumbul ${ }^{4}$ \\ ${ }^{1}$ Yeditepe University, Faculty of Medicine, Department of General Surgery, Istanbul, Turkey \\ ${ }^{2}$ Yeditepe University, Faculty of Engineering, Department of Genetic and Bioengineering, Istanbul, Turkey \\ ${ }^{3}$ Yeditepe University, Medical School Student, Istanbul, Turkey \\ ${ }^{4}$ Yeditepe University, Department of Histology and Embriology, Istanbul, Turkey
}

Correspondence should be addressed to Erhan Aysan; erhanaysan@hotmail.com

Received 19 November 2019; Accepted 12 March 2020; Published 6 April 2020

Academic Editor: Thomas Herzog

Copyright ( $\odot 2020$ Erhan Aysan et al. This is an open access article distributed under the Creative Commons Attribution License, which permits unrestricted use, distribution, and reproduction in any medium, provided the original work is properly cited.

\begin{abstract}
Background. Postoperative peritoneal adhesions (PPA) are a serious problem for abdominal surgery. An effective remedy has not been found yet. New formulation of glycerol and sodium pentaborate may be able to solve the problem. Method. Female Wistar albino rats were randomly assigned into four equal groups. The adhesion model was created on the caecum anterior wall and covered with $2 \mathrm{ml} 0.9 \% \mathrm{NaCl}, 3 \%$ glycerol, $3 \%$ sodium pentaborate, and $3 \%$ glycerol plus $3 \%$ sodium pentaborate solutions in the groups, respectively. Two weeks later, the rats were sacrificed. PPA were graded macroscopically and microscopically. Results. Total adhesion scores of the $3 \%$ glycerol $+3 \%$ sodium pentaborate group were statistically different from the other groups for macroscopic and also microscopic evaluations $(p<0.001)$. Conclusion. $3 \%$ glycerol plus $3 \%$ sodium pentaborate as a new formulation has preventive effects on PPA with a synergistic mechanism.
\end{abstract}

\section{Introduction}

Postoperative peritoneal adhesion (PPA) is a serious problem in abdominal surgery. It is one of the most common causes of mechanical intestinal obstruction, female infertility, and pelvic pain [1-3]. PPA also causes serious health care expenditure [4]. Several products and techniques have been suggested to prevent PPA, but no effective remedy has been found.

Glycerol is a viscous liquid alcohol with a molecular weight of 92.09 daltons [3]. It dissolves in water and alcohols, but not in liquid hydrocarbons [5]. Glycerol is one of the most common molecules in living organisms, and it is also a central component of lipids. Fatty tissues consist of one molecule of glycerol combined with three molecules of fatty acids [6, 7]. Glycerol is used in medical, pharmaceutical, and personal care preparations, mainly as a means of improving smoothness, providing lubrication, and as a humectant (a hygroscopic substance) $[6,7]$. In a study conducted by our group, PPA prevention was shown using 1\% glycerol [8].
Boron is a very stable metal. Groundwater contains a small amount of boron. The richest sources of boron are fruits, vegetables, pulses, legumes, and nuts. The mean daily intake of boron in the diet is estimated to be about $1.2 \mathrm{mg} /$ day. As boron is very similar to the carbon atom, many carbon-based molecules are the same as the boron-based molecules [1]. The wound healing benefits of some types of boron compounds, especially sodium pentaborate, have been previously documented [9-14].

In this research, we aimed to investigate the effects of $3 \%$ glycerol and $3 \%$ sodium pentaborate compound on PPA prevention. We hypothesized that the new formulation may be more beneficial for the prevention of PPA than $1 \%$ glycerol due to synergistic activity.

\section{Method}

The study protocol was approved by the local animal ethics committee. Twenty-eight female Wistar albino rats (mean weight $270 \pm 35 \mathrm{~g}$, mean age 6 months, out bred) were 
randomly assigned into four groups of 7 rats each, calculated to yield results with 0.9 power and 0.05 confidence interval.

Following overnight fasting, all animals were anesthetized by intramuscular $75 \mathrm{mg} / \mathrm{kg}$ ketamine. The midabdominal surfaces were shaved and prepared with povidone-iodine. For each rat, the peritoneal cavity was entered through a $2-\mathrm{cm}$ midline incision, and the caecum was mobilized and the anterior surface was scraped with sterile dry gauze until serosal petechias appeared (scraping model) [1]. The created surfaces from the adhesion model were covered with $2 \mathrm{ml} 0.9 \% \mathrm{NaCl}, 3 \%$ glycerol, 3\% sodium pentaborate, and $3 \%$ glycerol plus $3 \%$ sodium pentaborate solutions in the groups, respectively.

The abdominal incisions were closed in two layers with continuous $3 / 0$ polypropylene sutures. The animals were then placed on the regular pellet (state manufacturer) food. Two weeks later, the rats were sacrificed with an overdose of ketamine, and the peritoneal cavities were entered with a reversed U-shaped incision of the anterior abdominal wall, which was retracted caudally to provide maximal exposure. Adhesions were graded as $0-3$ according to size and severity scoring [15] (Table 1).

The injured caecum surfaces with adhesion formations were excised and put into formaldehyde solutions. The specimens were fixed in 70\% alcohol, dehydrated, and embedded in paraffin wax. Sections were cut at a thickness of $5 \mathrm{~mm}$, stained with hematoxylin and eosin, and evaluated according to histopathologic fibrosis scoring [16] (Table 2). Total adhesion scores were evaluated and compared for the groups. The total adhesion score was calculated by multiplying the number of animals and the adhesion grades.

2.1. Statistical Analysis. Statistical analyses were performed using GraphPad Prisma V.10 software. Results were evaluated with a confidence interval of $95 \%$ and $p<0.05$. The Chi-square and Fisher tests were used for intergroup comparisons.

\section{Results}

Grades of macroscopic adhesion size and severity of the groups are shown in Tables 3 and 4. Grades of histopathologic fibrosis are shown in Table 5. Total adhesion scores of the $3 \%$ glycerol plus $3 \%$ sodium pentaborate group were statistically different from the other groups for macroscopic and also microscopic evaluations $(p<0.001$, Figure 1). The total macroscopic adhesion size score was statistically different in the $3 \%$ glycerol group $(p<0.001$, Figure 2) but not in the $3 \%$ sodium pentaborate group $(p>0.05$, Figure 3) compared with the $0.9 \% \mathrm{NaCl}$ group (Figure 4), respectively. The total macroscopic adhesion severity score was statistically different in the $3 \%$ glycerol group $(p<0.001)$ and also the $3 \%$ sodium pentaborate group $(p<0.05)$ compared with the $0.9 \% \mathrm{NaCl}$ group respectively. Total histopathologic fibrosis scores of the $3 \%$ glycerol and the $3 \%$ sodium pentaborate groups were the same and statistically different $(p<0.05)$ form the $0.9 \% \mathrm{NaCl}$ group.

\section{Discussion}

Trauma to living tissue causes a wound and triggers the start of the wound healing process. Wound healing occurs in three stages: inflammation, fibrosis, and maturation. Many proteins, molecules, cells, and cytokines are involved in the inflammation stage. The effect and mechanism of action of many of these have not been elucidated. Many molecules that emerge during inflammation have adhesive properties. The amount of adhesion formation is related to the severity and duration of the inflammation $[17,18]$. In the second stage of wound healing, fibrinogen proteins turn into thin fibrin fibers. These fibers then combine to form thicker and stronger collagen fibers. The maturation stage is the continuation of the fibrosis stage, where collagen fibers are organized. Collagen fibers are characterized by forming strong bands (adhesions) to the surfaces that they contact regardless of whether they belong to the wound or not $[17,19]$.

Many peritoneal manipulations (holding, pulling, stretching, and cutting) cause a wound. After this, the peritoneal wound healing process starts and always leads to PPA formation [1, 2, 20-22]. Several techniques, substances, and agents have been investigated to prevent PPA. These include various surgical methods, minimal invasive and laparoscopic techniques, pharmacological agents targeting the inflammatory response and/or fibrin formation, liquids to form a mechanical barrier between mesothelial surfaces, gels and solids, etc. Although some techniques or agents have proven useful, none have shown complete success [1, 20-23].

Basic principles for PPA prevention are reduction of inflammation (anti-inflammatory effect), acceleration of wound healing, and separation of the wound surfaces from surrounding tissues. Although these principles are known, many studies have been conducted to prevent PPA, but an effective product has yet to be discovered [16, 24-26].

We have also studied on this topic previously [8] and revealed that $1 \%$ glycerol is effective for the prevention of PPA. According to macromolecular structure, when injected into the tissues or spaces into the body, absorption of glycerol via capillaries is difficult. So, glycerol stays in the injected area for a long period of time [5-7]. As glycerol is a very biocompatible molecule, it is used in many pharmaceutical, cosmetic, and prosthetic products [6, 7, 27-29]. Glycerol is frequently added to peritoneal dialysis solutions. Mortier et al. reported that glycerol augments the efficacy of peritoneal dialysis and ensures a protective effect on peritoneal surfaces [30]. In our previous study, we revealed that $1 \%$ glycerol was effective for the prevention of PPA by mechanically separating the peritoneal healing surfaces from surrounding tissues [8].

Mechanical separations using gelatinous liquids with high viscosity have yielded relatively high success rates. Gelatinous liquids are thought to prevent the formation of PPA by providing a protective layer between the surfaces and preventing contact between deperitonized surfaces and surrounding tissues $[31,32]$. In vitro studies have shown that cells are located on two sides of a high viscosity gelatinous 
TABle 1: Definitions of macroscopic adhesion scoring.

\begin{tabular}{lcc}
\hline Grades & Adhesion size definiton & Adhesion severity definition \\
\hline 0 & No adhesion & No adhesion \\
1 & Adhesions cover a maximum of $1 / 3$ of the model area & Spontaneously separating adhesion \\
2 & Adhesions cover a maximum of $2 / 3$ of the model area & Separation of adhesion with traction \\
3 & Whole model area covered with adhesions & Separation of adhesion with sharp dissection \\
\hline
\end{tabular}

TABLe 2: Definitions of histopathologic fibrosis scoring.

\begin{tabular}{lc}
\hline Grades & Definition \\
\hline 0 & No fibrosis (no fibroblasts and/or collagen fibers) \\
1 & Slight fibrosis (few fibroblasts and/or collagen fibers) \\
2 & Median fibrosis (more fibroblasts and/or collagen fibers) \\
3 & Severe fibrosis (lots of fibroblasts and/or collagen fibers) \\
\hline
\end{tabular}

TABle 3: Grades of macroscopic adhesion size.

\begin{tabular}{lcccc}
\hline Grade & $0.9 \% \mathrm{NaCl}$ group & $\begin{array}{c}3 \% \text { glycerol group } \\
(n)\end{array}$ & $\begin{array}{c}3 \% \text { sodium pentaborate group } \\
(n)\end{array}$ & $\begin{array}{c}3 \% \text { glycerol plus 3\% sodium pentaborate group } \\
(n)\end{array}$ \\
\hline 0 & - & 2 & - & 5 \\
1 & - & 4 & 2 & 2 \\
2 & 1 & 1 & 3 & - \\
3 & 6 & - & 2 & 2 \\
Total & 19 & 6 & 14 & 2 \\
score & & & & \\
\hline
\end{tabular}

TABLE 4: Grades of macroscopic adhesion severity.

\begin{tabular}{|c|c|c|c|c|}
\hline Grade & $\begin{array}{c}\% 0.9 \mathrm{NaCl} \text { group } \\
(n)\end{array}$ & $3 \%$ glycerol group $(n)$ & $\begin{array}{l}3 \% \text { sodium pentaborate group } \\
(n)\end{array}$ & $\begin{array}{l}3 \% \text { glycerol plus } 3 \% \text { sodium pentaborate group } \\
\qquad(n)\end{array}$ \\
\hline 0 & - & 2 & - & 5 \\
\hline 1 & - & 3 & 2 & 2 \\
\hline 2 & - & 2 & 4 & - \\
\hline 3 & 7 & - & 1 & - \\
\hline \multicolumn{5}{|l|}{ Total } \\
\hline Score & 21 & 7 & 13 & 2 \\
\hline
\end{tabular}

TABLE 5: Grades of histopathologic fibrosis.

\begin{tabular}{|c|c|c|c|c|}
\hline Grade & $\begin{array}{c}\% 0.9 \mathrm{NaCl} \text { group } \\
(n)\end{array}$ & $\begin{array}{l}3 \% \text { glycerol group } \\
(n)\end{array}$ & $\begin{array}{l}\text { 3\% sodium pentaborate group } \\
(n)\end{array}$ & $\begin{array}{l}3 \% \text { glycerol plus } 3 \% \text { sodium pentaborate group } \\
(n)\end{array}$ \\
\hline 0 & - & 2 & - & 5 \\
\hline 1 & - & 2 & 5 & 2 \\
\hline 2 & 2 & 1 & 1 & - \\
\hline 3 & 5 & 2 & 1 & - \\
\hline $\begin{array}{l}\text { Total } \\
\text { score }\end{array}$ & 17 & 10 & 10 & 1 \\
\hline
\end{tabular}

liquid environment without movement to each other [33]. In this study, we increased the viscosity (3\%) of glycerol to prolong the absorption time and to reveal a longer mechanical separation effect.

The positive effects of various boron compounds on the wound healing process have been demonstrated before [10-12]. In in-vitro and in-vivo studies performed by our group, sodium pentaborate has been shown to exert antiinflammatory effects through cell proliferation, cell migration, and growth factor expression pathways and to accelerate wound healing in different wound models [12, 13]. In a prospective randomized clinical trial, we also revealed that sodium pentaborate gel prevents radiation induced dermatitis in breast cancer patients [14]. 


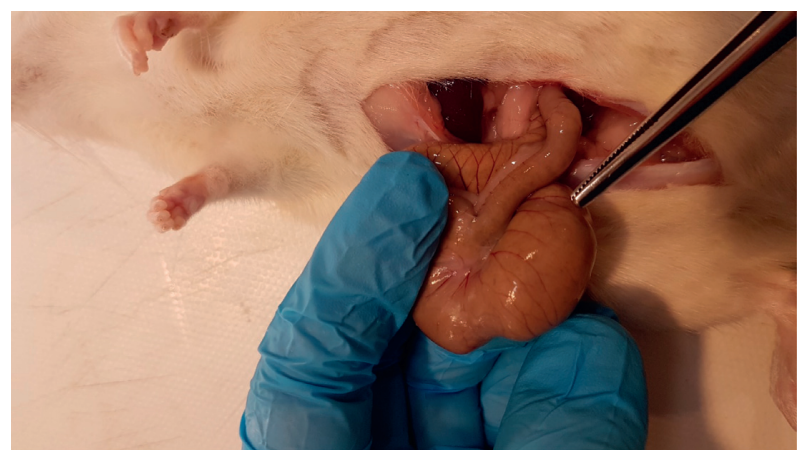

Figure 1: Macroscopic adhesion score 0 case from the 3\% glycerol plus $3 \%$ sodium pentaborate group.

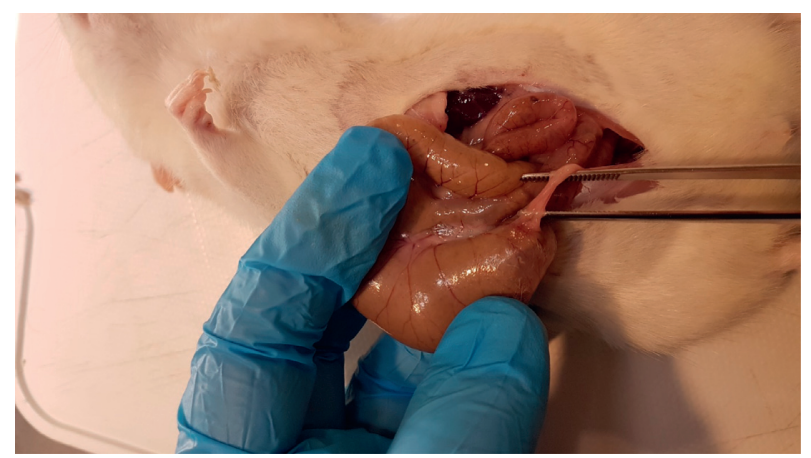

Figure 2: Macroscopic adhesion score 1 case from the 3\% glycerol group.

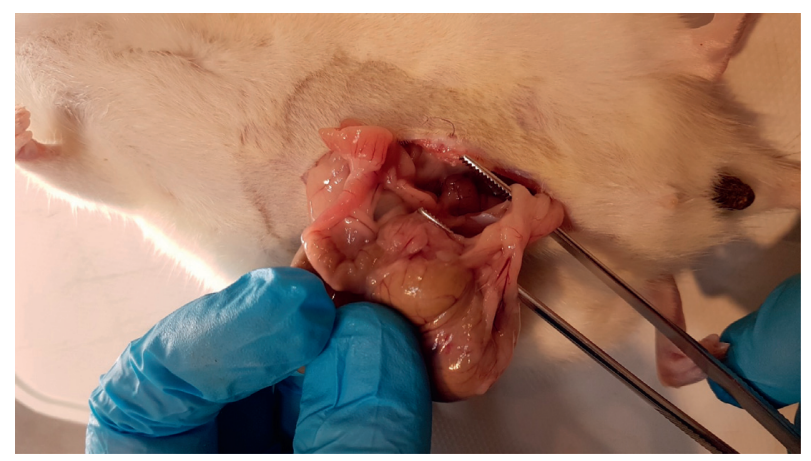

Figure 3: Macroscopic adhesion score 2 case from the 3\% sodium pentaborate group.

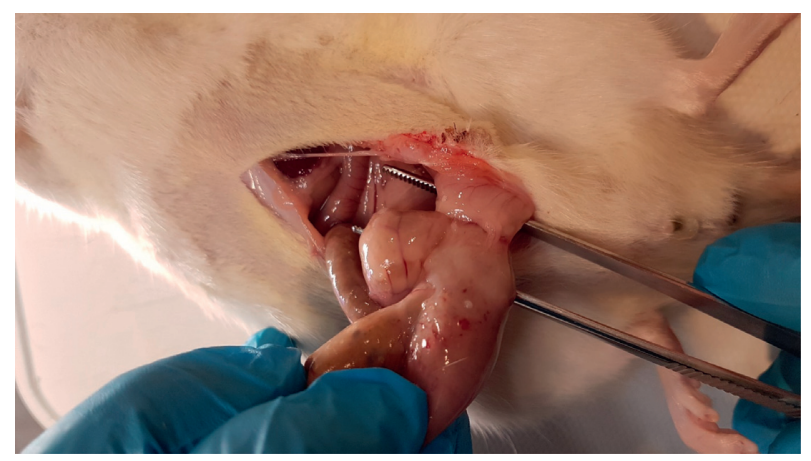

Figure 4: Macroscopic adhesion score 3 case from the control group.
In this study, we observed that $3 \%$ sodium pentaborate or $3 \%$ glycerol did not prevent PPA formation when either was applied to the peritoneal surface. However, when we applied both molecules together, we created the synergistic effect and PPA was statistically reduced.

We conclude that according to the anti-inflammatory and wound healing acceleration activity of sodium pentaborate, less inflammation occurred and less adhesive molecules were produced with faster wound healing. Meanwhile, 3\% dense glycerol ensured effective mechanical separation around the wound healing environment. This synergistic activity revealed less PPA formation.

The results of a macroscopically low PPA score with a high histopathologic fibrosis grade in the glycerol group and, in contrast, a macroscopically high PPA score with low histopathologic fibrosis grade in the sodium pentaborate group support our hypothesis.

In conclusion, $3 \%$ glycerol plus $3 \%$ sodium pentaborate as a new formulation has effective preventive effects on PPA by a synergistic mechanism. In order to use this new formulation in abdominal surgical interventions, its effects on different surgical procedures, especially anastomotic healing, should be evaluated.

\section{Data Availability}

The data used to support the findings of this study are included within the article.

\section{Conflicts of Interest}

The authors declare that they have no conflicts of interest.

\section{Acknowledgments}

The authors highly appreciate the efforts of Monica Ann Malt, MSN, RN, and CPAN (Bezmialem Vakif University, Turkey) in language editing of this paper.

\section{References}

[1] D. L. Anderson, W. C. Cunningham, and T. R. Lindstrom, "Concentrations and intakes of $\mathrm{H}, \mathrm{B}, \mathrm{S}, \mathrm{K}, \mathrm{Na}, \mathrm{Cl}$, and $\mathrm{NaCl}$ in foods," Journal of Food Composition and Analysis, vol. 7, no. 1-2, pp. 59-82, 1994.

[2] S. Altieri, S. Bortolussi, P. Bruschi et al., "Neutron autoradiography imaging of selective boron uptake in human metastatic tumours," Applied Radiation and Isotopes, vol. 66, no. 12 , pp. $1850-1855,2008$.

[3] P. Hunter, "Not boring at all," EMBO Reports, vol. 10, no. 2, pp. 125-128, 2009.

[4] K. Warrington, "The effects of boric acid and borax on the broad bean and certain other plants," Annals of Botany, vol. 37, no. 4, pp. 629-672, 1923.

[5] A. F. Rossi, R. D. Miles, B. L. Damron, and L. K. Flunker, "Effects of dietary boron supplementation on broilers," Poultry Science, vol. 72, no. 11, pp. 2124-2130, 1993.

[6] M. Watanabe, T. Iida, Y. Aizawa, T. M. Aida, and H. Inomata, "Acrolein synthesis from glycerol in hot-compressed water," Bioresource Technology, vol. 98, no. 6, pp. 1285-1290, 2007. 
[7] S. S. Yazdani and R. Gonzalez, "Anaerobic fermentation of glycerol: a path to economic viability for the biofuels industry," Current Opinion in Biotechnology, vol. 18, no. 3, pp. 213-219, 2007.

[8] E. Aysan, H. Bektas, and A. Kaygusuz, "Efficacy of glycerol in preventing postoperative peritoneal adhesions," Journal of Obstetrics and Gynaecology Research, vol. 36, no. 3, pp. 639$645,2010$.

[9] K. Kulprachakarn, S. Ounjaijean, J. Wungrath, R. Mani, and K. Rerkasem, "Micronutrients and natural compounds status and their effects on wound healing in the diabetic foot ulcer," The International Journal of Lower Extremity Wounds, vol. 16, no. 4, pp. 244-250, 2017.

[10] L. Pizzorno, "Nothing boring about boron," Integrative Medicine (Encinitas, Calif.), vol. 14, no. 14, pp. 35-48, 2015.

[11] M. Benderdour, T. Bui-Van, A. Dicko, and F. Belleville, "In vivo and in vitro effects of boron and boronated compounds," Journal of Trace Elements in Medicine and Biology, vol. 12, no. 1, pp. 2-7, 1998.

[12] S. Demirci, A. Doğan, S. Aydın, E. Ç. Dülger, and F. Şahin, "Boron promotes streptozotocin-induced diabetic wound healing: roles in cell proliferation and migration, growth factor expression, and inflammation," Molecular and Cellular Biochemistry, vol. 417, no. 1-2, pp. 119-133, 2016.

[13] S. Demirci, A. Doğan, E. Karakuş et al., "Boron and poloxamer (F68 and F127) containing hydrogel formulation for burn wound healing," Biological Trace Element Research, vol. 168, no. 1, pp. 169-180, 2015.

[14] E. Aysan, U. O. Idiz, L. Elmas, E. K. Saglam, Z. Akgun, and S. B. Yucel, "Effects of boron-based gel on radiation-induced dermatitis in breast cancer: a double-blind, placebo-controlled trial," Journal of Investigative Surgery, vol. 30, no. 3, pp. 187-192, 2017.

[15] S. V. Pismensky, Z. R. Kalzhanov, M. Y. Eliseeva, I. P. Kosmas, and O. A. Mynbaev, "Severe inflammatory reaction induced by peritoneal trauma is the key driving mechanism of postoperative adhesion formation," BMC Surgery, vol. 11, no. 1, p. 30, 2011.

[16] A. Sahbaz, O. Aynioglu, H. Isik et al., "Bromelain: a natural proteolytic for intra-abdominal adhesion prevention," International Journal of Surgery, vol. 14, pp. 7-11, 2015.

[17] P. Price, "How can we improve adherence?" Diabetes/ Metabolism Research and Reviews, vol. 32, no. Suppl 1, pp. 201-205, 2016.

[18] C. S. Garwood and J. S. Steinberg, "What's new in wound treatment: a critical appraisal," Diabetes/Metabolism Research and Reviews, vol. 32, no. Suppl 1, pp. 268-274, 2016.

[19] T. Velnar, T. Bailey, and V. Smrkolj, "The wound healing process: an overview of the cellular and molecular mechanisms," Journal of International Medical Research, vol. 37, no. 5, pp. 1528-1542, 2009.

[20] A. K. Davey and P. J. Maher, "Surgical adhesions: a timely update, a great challenge for the future," Journal of Minimally Invasive Gynecology, vol. 14, no. 1, pp. 15-22, 2007.

[21] H. Ellis, "The causes and prevention of intestinal adhesions," British Journal of Surgery, vol. 69, no. 5, pp. 241-243, 1982.

[22] L. Holmdahl, B. Risberg, and D. E. Beck, "Adhesions: pathogenesis and prevention-panel discussion and summary," European Journal of Surgery, vol. 577, pp. 56-62, 1997.

[23] T. Liakakos, N. Thomakos, P. M. Fine, C. Dervenis, and R. L. Young, "Peritoneal adhesions: etiology, pathophysiology, and clinical significance," Digestive Surgery, vol. 18, no. 4, pp. 260-273, 2001.
[24] A. Hershalg, M. P. Diamond, and A. H. DeCherney, "Adhesiolysis," Clinical Obstetrics and Gynecology, vol. 34, no. 2, pp. 395-398, 1991.

[25] L. Holmdahl and B. Risberg, "Adhesions: prevention and complications in general surgery," The European Journal of Surgery = Acta Chirurgica, vol. 163, no. 3, pp. 169-174, 1997.

[26] L. Ott, M. Bicker, and H. Vogel, "Catalytic dehydration of glycerol in sub- and supercritical water: a new chemical process for acrolein production," Green Chemistry, vol. 8, no. 2, pp. 214-220, 2006.

[27] J. M. Bellón, N. Serrano, M. Rodríguez, N. García-Honduvilla, G. Pascual, and J. Buján, "Composite prostheses used to repair abdominal wall defects: physical or chemical adhesion barriers?" Journal of Biomedical Materials Research Part B: Applied Biomaterials, vol. 74B, no. 2, pp. 718-724, 2005.

[28] J. M. Bellón, M. Rodríguez, N. García-Honduvilla, G. Pascual, V. Gómez Gil, and J. Buján, "Peritoneal effects of prosthetic meshes used to repair abdominal wall defects: monitoring adhesions by sequential laparoscopy," Journal of Laparoendoscopic \& Advanced Surgical Techniques, vol. 17, no. 2, pp. 160-166, 2007.

[29] J. W. A. Burger, J. A. Halm, A. R. Wijsmuller, S. T. Raa, and J. Jeekel, "Evaluation of new prosthetic meshes for ventral hernia repair," Surgical Endoscopy, vol. 20, no. 8, pp. 13201325, 2006.

[30] S. Mortier, D. Faict, L. N. GerickeM, and A. De Vriese, "Effects of new peritoneal dialysis solutions on leukocyte recruitment in the rat peritoneal membrane," Nephron Experimental Nephrology, vol. 101, no. 4, pp. e139-e145, 2005.

[31] M. Wallwiener, S. Brucker, H. Hierlemann, C. Brochhausen, E. Solomayer, and C. Wallwiener, "Innovative barriers for peritoneal adhesion prevention: liquid or solid? A rat uterine horn model," Fertility and Sterility, vol. 86, no. 4, pp. 12661276, 2006.

[32] G. S. Dizerega, S. Cortese, K. E. Rodgers et al., "A modern biomaterial for adhesion prevention," Journal of Biomedical Materials Research Part B: Applied Biomaterials, vol. 81B, no. 1, pp. 239-250, 2007.

[33] R. Folger, L. Weiss, D. Glaves, J. R. Subjeck, and J. P. Harlos, "Translational movements of macrophages through media of different viscosities," Journal of Cell Science, vol. 31, no. 31, pp. 245-257, 1978. 